\title{
Letter
}

Nina Ehlert, Tammo Lüßenhop, Ilka Krueger, Armin Feldhoff, Muhammad Badar, Peter P. Mueller, Martin Stieve ${ }^{a}$, Thomas Lenarz and Peter Behrens*

\section{Nanoporous silica coatings on implant surfaces: characterization, stability, biocompatibility and drug release properties}

\begin{abstract}
Nanoporous silica coatings for drug release purposes were prepared on medical implants. As substrate, we chose Bioverit ${ }^{\circledR}$ II, which is a commercial available glass-mica ceramic implant material. The coating was prepared by a dip-coating technique in which long-chain organic molecules act as placeholders for the pores. Characterization of the coatings by scanning transmission electron microscopy and X-ray diffraction showed a disordered nanoporous system with a layer thickness of $30-150 \mathrm{~nm}$. The nanoporous structure was stable for about $12 \mathrm{~h}$ in a typical cell culture medium and rearranged to a packing of silica nanoparticles. The coating allowed cell attachment and showed excellent biocompatibility in cell culture tests independently of the particular cell type examined. In vivo, implant-tissue interactions were examined in the middle ear in a novel mouse model. Whole genome expression profiling showed no persisting inflammatory response in the presence of the implants. Release profiles of the antibiotic ciprofloxacin demonstrated that the coating is suitable for a local drug delivery. The drug loading capacity could be drastically increased after sulfonic acid modification of the Bioverit ${ }^{\circledR}$ II surface.
\end{abstract}

Keywords: drug delivery; gene array expression profile; glass ceramics; mouse middle ear model; nanoporous silica.

aPresent address: Clinic for Laryngology, Rhinology and Otology, University Medical Center Schleswig-Holstein, 23538 Lübeck, Germany *Corresponding author: Peter Behrens, Callinstr. 9, 30167 Hannover, Germany, Phone: +49 511762 3697, Fax: +49 511762 3600,

E-mail: Peter.Behrens@acb.uni-hannover.de

Tammo Lüßenhop, Nina Ehlert and Peter Behrens: Leibniz University of Hannover, Institute of Inorganic Chemistry, 30167 Hannover, Germany; and Centre for Solid State Chemistry and New Materials (ZFM), 30167 Hannover, Germany

Ilka Krueger: Leibniz University of Hannover, Institute of Inorganic Chemistry, 30167 Hannover, Germany

Armin Feldhoff: Leibniz University of Hannover, Institute of Physical Chemistry and Electrochemistry, 30167 Hannover, Germany; and Centre for Solid State Chemistry and New Materials (ZFM), 30167 Hannover, Germany
Muhammad Badar and Peter P. Mueller: Helmholtz-Centre for Infection Research, 38124 Braunschweig, Germany Martin Stieve and Thomas Lenarz: Clinic for Laryngology, Rhinology and Otology, Hannover Medical School, 30625 Hannover, Germany

\section{Introduction}

Glass-ceramic materials are known to have a very good tissue compatibility [1-3]. Typical applications are in non-load bearing areas such as head and neck surgery, bone substitution after cancer treatment, and in ossicular chain reconstruction surgery [4]. Bioverit ${ }^{\circledR}$ II is an advanced glass-mica ceramic implant material that is highly biocompatible, insoluble and corrosion-resistant and possesses excellent machining properties [5]. Furthermore, Bioverit ${ }^{\circledR}$ II is clinically well established mainly as a bone replacement material in skull and middle ear reconstructive surgery [6-9]. Nevertheless, no presently available material is optimally suited to fulfill the diverse requirements of all possible applications. As an alternative to the search for entirely novel materials, an attractive option is the coating of clinically established implant materials to add specific functions to influence the implant-issue interaction. In particular, porous coatings can serve as drug reservoirs.

Besides the coating material itself various surface structures can influence the biological properties of an implant [10]. As an example for nanostructured materials, nanoporous silica materials $[11,12]$ have been proposed for applications in bone reconstruction [13, 14]. Nanoporous materials with pores in the range from 2 to $15 \mathrm{~nm}$ can be prepared by silica sol-gel processes. In the general materials chemistry literature, these materials are usually designated as 'mesoporous'; however, in the biological context of these investigations we prefer the term 'nanoporous'. Normally, these materials 
are produced by solution-phase synthesis in form of a powder or as nanoparticles [15], but it is difficult to envisage how these can be applied with a pre-formed implant or prosthesis. Further developments showed that nanoporous silica materials can be produced as thin films on various substrates $[16,17]$ and that these films are suitable for drug release applications [18]. For these reasons, we focused on establishing a nanoporous silica film on a ceramic or glass-ceramic surface. The main features of nanoporous silica coatings are their excellent biocompatibility, the increased exposed surface area with respect to dense coatings, the corresponding increase in functional silanol (Si-OH) surface groups available for chemical modification, and the interior pore space, which could be used as a depot for local drug delivery.

With regard to that option and the numerous problems with postoperative implant-associated infections in implant surgery, a nanoporous silica coating with the possibility for a controlled drug release was developed [19]. Infections in implant surgery are caused by bacteria which are already present in the patient, or which are introduced to the implantation site during the operation [20]. However, these infections can spread from the implantation area and may thus necessitate a further treatment with antibiotics. Normally, such treatments are applied systemically, which is stressful for the body and can cause harmful side effects as well as the formation of a bacterial resistance. Additionally, it is possible that a systemic treatment of the infections may be insufficient in case of the formation of a biofilm on the implant surface [21]. Therefore, it would be useful to equip the prosthesis with a reservoir of antibiotics in order to fight the infection with a sufficient dose at the point of infection and suppress the formation of a biofilm on the implant. In the special case of middle ear prostheses, often chronic infections are occurring. Here, it would be a great advantage to immediately fight bacteria and support in that way the healing process after implantation.

Here, we report about the preparation and a comprehensive in vitro and in vivo evaluation of a nanoporous silica coating on a medical implant material. We chose the glass mica-ceramic Bioverit ${ }^{\circledR}$ II as base material for the coating, as it is a commercially available implant material for a variety of applications, and is for example often used for the functional replacement of the middle ear ossicular chain. In preliminary in vitro investigations and for thorough characterization, standard glass slides were used as substrates. A reliable coating procedure was developed and the structure and morphology of the coatings were determined. The nanoporous coating was investigated by, scanning transmission electron microscopy (STEM) and X-ray diffraction (XRD). The coating was tested with regard to its stability in physiological medium and the properties of the nanoporous silica coating based drug release system were determined. Furthermore, the interactions of the coating with cultured cells and eventually with relevant tissues in animal models were evaluated in molecular detail. The release of ciprofloxacin was studied from Bioverit ${ }^{\circledast}$ II platelets coated with nanoporous silica. Ciprofloxacin is an antibiotic which is used to treat middle ear infections caused by Pseudomonas aeruginosa, a pathogen typical for such infections.

\section{Results and discussion}

\section{Preparation of nanoporous silica coatings}

Nanostructured silica films were selected as a biocompatible coating material. When tetraethoxysilane is hydrolyzed in an aqueous medium, monosilicic acid forms an amorphous silica network upon evaporation of the liquid phase. In an approach designated as structure-directed synthesis, amphiphilic molecules can be used to influence the structure formation of amorphous silica [22-24]. The organic amphiphilic molecules can form micelles with cylindrical or spherical shape and lyotropic liquid crystal phases. The silica network formation has been proposed to take place around the micellar aggregates of the amphiphilic molecules, resulting in an as-synthesized organic-inorganic hybrid nanostructured solid phase [25]. Removal of the organic placeholder molecules from the as-synthesized coating by oxidation has been demonstrated to yield nanoporous silica with typical pore sizes between 2 and $10 \mathrm{~nm}$. In order to coat implants with nanoporous silica, either dip-coating or spray-coating procedures can be applied. The dip-coating procedure for the production of nanoporous silica films has been investigated intensively and has been shown to follow the evaporation-induced self-assembly (EISA) mechanism [26]. In this work, glass slides and Bioverit ${ }^{\circledR}$ II samples were both coated by an established dip-coating procedure using the non-ionic amphiphilic compound $\mathrm{EO}_{20} \mathrm{PO}_{70} \mathrm{EO}_{20}[19,27$, $28]$. The coating was air-dried resulting in the as-synthesized coating. On Bioverit ${ }^{\circledR}$ II supports with their rough surface structure, the procedure was repeated twice to ensure complete coatings. Subsequently, the silica was dried and the structure-directing molecules which have acted as organic placeholders, were removed by calcinations (heating in air at $415^{\circ} \mathrm{C}$ ). 


\section{X-ray diffraction}

The characteristic repeat size of the nanostructured silica layers generates $\mathrm{X}$-ray diffraction reflections at low $2 \theta$ values. The as-synthesized films show a reflection at $1.1^{\circ} 2 \theta$ which is shifted to $1.6^{\circ} 2 \theta$ for the calcined ones (Figure 1), reflecting regular structures of $8.0 \mathrm{~nm}$ and $5.5 \mathrm{~nm}$ repeat size, respectively. Furthermore, the nanoporous material exhibit a very broad reflection at $3^{\circ} 2 \theta$.

These dimensions are characteristic for the supramolecular arrangements of the organic placeholder molecules added to the silica solution. Calcination reduced the dimensions of these structures to about $66 \%$ of the size of the as synthesized coatings. It is well established that the removal of the organic molecules by calcination from bulk amphiphile-templated nanostructured silica leads to a reduction of the dimension of the nanostructures due to increased silica condensation [11]. The singular reflections observed in the X-ray diffraction patterns are evoked by the electron density contrast between the silica wall

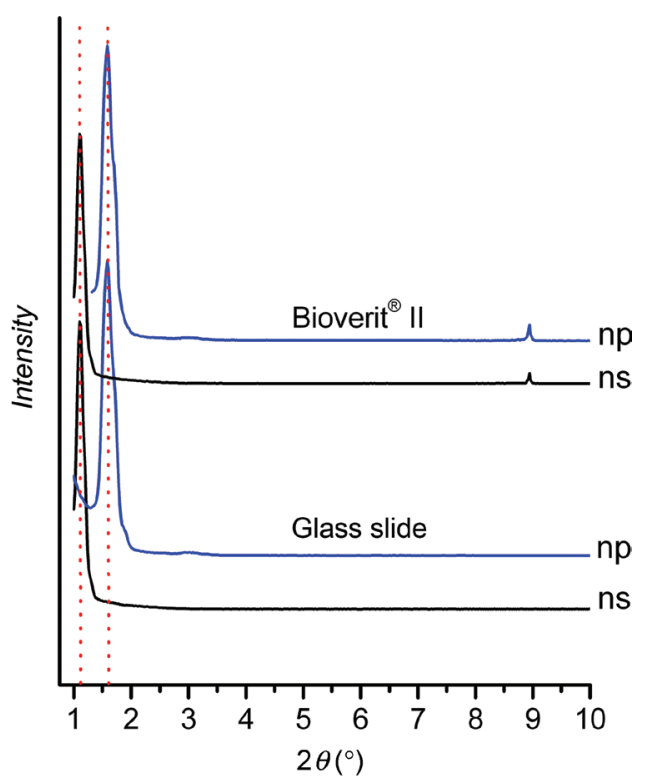

Figure 1 The presence of amphiphilic polymeric molecules during the synthesis of silica coatings results in the generation of regular structures in the nanometer range which are reflected in the X-ray diffractograms of silica films on glass slides (bottom two lines) and on Bioverit ${ }^{\circledast}$ II substrates (top two lines; ns: as-synthesized (nano-structured) layers still containing the amphiphilic structuredirecting agent; np: nanoporous layers after removal of the amphiphilic structure-directing agent. The diffraction patterns show a broad major peak at $1.1^{\circ} 2 \theta$ for the as-synthesized and $1.6^{\circ} 2 \theta$ for the nanoporous material, reflecting regular structures of $8.0 \mathrm{~nm}$ and $5.5 \mathrm{~nm}$ repeat size, respectively. In the patterns of the Bioverit ${ }^{\circledR}$ II-based samples, the sharp peak at ca. $9^{\circ} 2 \theta$ stems from the crystalline parts of the glass-mica ceramic. material and either the organic material or, after calcination, the empty pores. Their presence reflects a regular pore diameter and distance between pores. As apart from the broad reflections no other significant diffraction phenomena can be observed at low $2 \theta$ values, the pores in the coatings we produced have no ordered arrangement, as described previously $[19,27,28]$, as specific periodic pore packings (as hexagonal, cubic or lamellar) would lead to additional reflections. The mesopore structure is thus disordered, similar to bulk nanoporous materials of the LMU-1 [24] or KIT-1 [29] type. The fact that the same reflections can be found on the coated Bioverit ${ }^{\circledR}$ II samples shows that the nanostructure of the silica film is present on the ceramic substrate as well. Additionally, the Bioverit ${ }^{\circledR}$ II samples exhibit another reflection at $9^{\circ} 2 \theta$ which is caused by the crystalline parts of the substrate material.

Overall, XRD results showed that disordered nanostructured silica coatings with a characteristic repeat unit were reproducibly obtained by the dip-coating technique and EISA.

\section{STEM studies}

In accordance to the XRD results, electron microscope images revealed a disordered arrangement of the nanoporous film (Figure 2).

The side-view of an intentionally broken layer shows the good attachment of the film on the glass substrate (Figure 2A). Having a closer look on the surface (Figure 2B), pore mouth openings can be seen on the surface and the pore system lying below can be accessed from them, an important requirement for drug release applications. In the cross section image (Figure $2 \mathrm{C}$ ) of the coating, pore channels can be observed which run primarily parallel to the substrate, but otherwise in different directions. These channels appear to be interrupted at irregular intervals. Clearly, the pore system is not ordered. The predominantly parallel orientation of the pore channels is caused by the liquid flow during dip-coating. From Figure $2 \mathrm{C}$, the thickness of the film can be determined to $40 \mathrm{~nm}$. Further investigations showed that the thickness of one layer is between 30 and $150 \mathrm{~nm}$ and the inner surface area of the film is increased to $11.2 \mathrm{~cm}^{2}$ per $\mathrm{cm}^{2}$ of the substrate [19].

In Figure 3, an STEM cross-section micrograph of the nanoporous silica film on a Bioverit ${ }^{\circledR}$ II substrate can be seen. The irregular nanoporous structure of the film can be clearly recognized here as well, with a pore size similar as observed on films on glass slides. The porous silica film fills essentially all the craters and cavities of the surface 

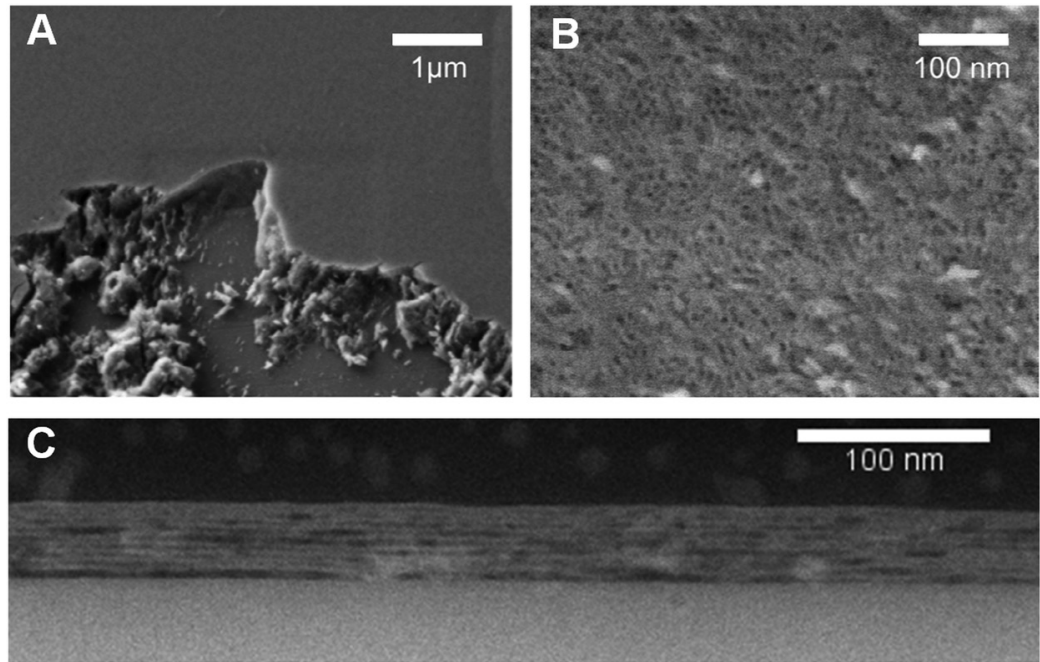

Figure 2 SEM and STEM images of a single nanoporous silica layer on a glass slide substrate. (A) SEM side-view of an intentionally broken layer, (B) SEM view on the surface showing open pore mouths of the structure, (C) STEM cross-section of the film revealing the disordered interrupted pore channels.

of the ceramic material and is apparently everywhere in close contact to the coating, despite of the rough surface topography of the Bioverit ${ }^{\circledR}$ II material. This roughness also accounts for the fact that the predominant orientation of the pore channels as described for the glass substrates can only be found when the pores are in direct contact to the surface. Farther from the surface, the nanoporous silica has an irregular pore system.

\section{Stability tests}

The stability of nanoporous silica thin films has been studied before by ellipsometry porosimetry and X-ray photoelectron spectroscopy. It was found that unfunctionalized films dissolved within hours [30]. We studied the stability of our films using XRD and electron microscope techniques.

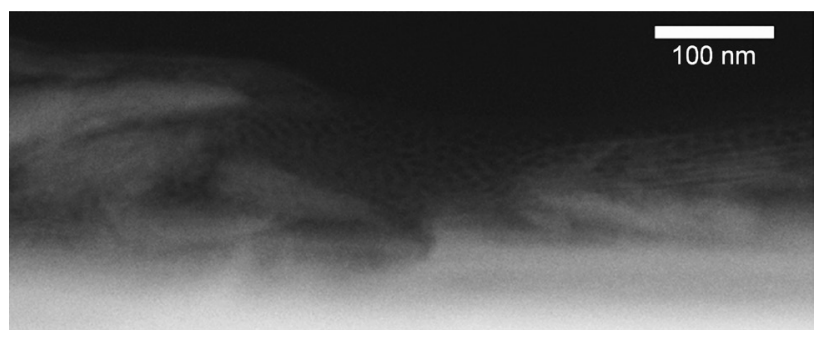

Figure 3 STEM image of a cross-section of the nanoporous silica film on Bioverit ${ }^{\circledR}$ II substrates, showing at the bottom the ceramic (white) and the disordered nanoporous structure of the coating.
The films were exposed to phosphate buffered saline (PBS) with $10 \%(\mathrm{v} / \mathrm{v})$ fetal calf serum for different times. XRD patterns measured on the so obtained samples revealed that the nanoporous structure of the film is destroyed, showing different successive phases (Figure 4) [28]. Within the first $6 \mathrm{~h}$ of incubation the intensity of the reflection at $1.6^{\circ} 2 \theta$ decreased, but was still visible after $12 \mathrm{~h}$ of exposure time. Concomitantly, the very broad reflection at $3^{\circ} 2 \theta$ vanishes and a broad reflection appears in the range from 2.0 to $2.5^{\circ} 2 \theta$. After $24 \mathrm{~h}$, no reflections can be discerned anymore.

Interestingly, profilometer measurements and microscopic controls on glass substrates showed that a silica film with reduced thickness is still present on the surface after at least $24 \mathrm{~h}$ of exposure to the medium. In view of these results, a sample that showed a reduction of the reflection intensity at $1.6^{\circ} 2 \theta$ and the appearance of the peak in the range from 2.0 to $2.5^{\circ} 2 \theta$ (corresponding to Figure 4, $12 \mathrm{~h}$ ) was freshly produced and transferred to STEM analysis immediately in order to clarify possible structural changes of the nanostructure (Figure 5).

STEM images of a cross-section of the film revealed that the nanostructure of the film rearranges to a packing of small silica nanoparticles with a size of $7-8 \mathrm{~nm}$. The uniform size of these nanoparticles and their regular packing, which is especially prominent near to the substrate (note the striations in Figure 5) probably causes the broad reflection in the range from 2.0 to $2.5^{\circ} 2 \theta$ in the XRD, referring to a repeat size of $4.2 \mathrm{~nm}$. The transformation between these two phases probably involves the partial dissolution of the nanoporous structure and reformation 


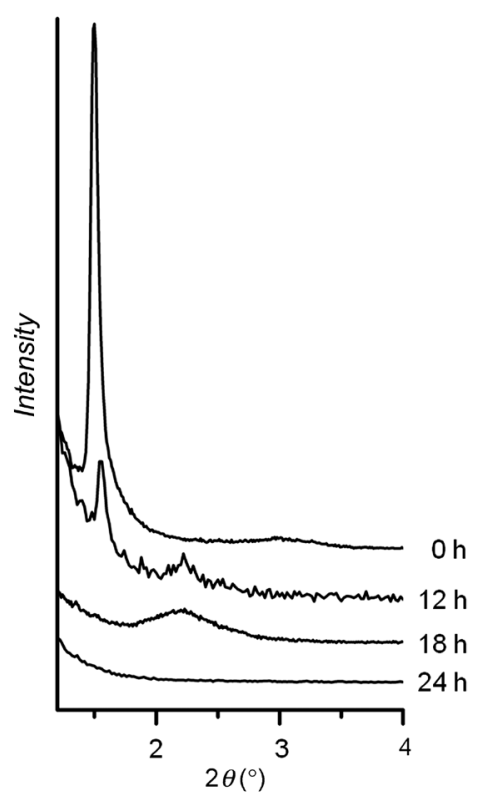

Figure 4 XRD patterns of a nanoporous silica coating on a glass slide before $(0 \mathrm{~h})$ and after exposure to $0.01 \mathrm{M}$ PBS with $10 \%(\mathrm{v} / \mathrm{v})$ fetal calf serum for different time intervals (12, 18 and $24 \mathrm{~h}$ ).

of the silica in the form of nanoparticles, possibly corresponding to an Ostwald ripening-type processes.

The rate of deterioration of nanoporous silica films is a function of the composition [30] and of modification. Silanization reactions with organic silanes as well as binding biomolecules to the coating can protect the film. For example, for a coating which was modified by the immobilization of alkaline phosphatase using the linker 3-aminopropyltrimethoxysilane [27], clear reflections from the nanopore structure can still be observed up to

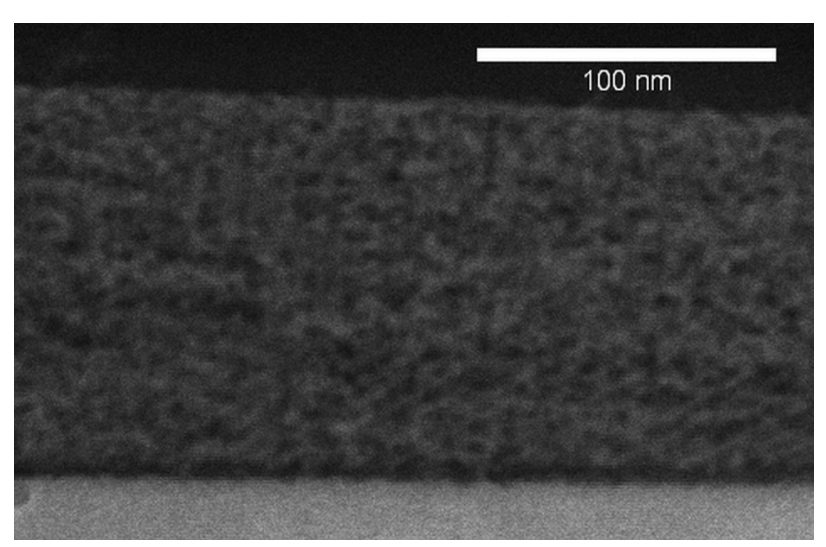

Figure 5 STEM image of a cross-section of a single nanoporous silica film exposed for $12 \mathrm{~h}$ to $0.01 \mathrm{M}$ PBS with $10 \%$ (v/v) fetal calf serum. After exposure to physiological medium the nanoporous structure of the silica film is destroyed. The film rearranges to a packing of silica nanoparticles with a size of 7-8 $\mathrm{nm}$.
$14 \mathrm{~h}$ of incubation. Afterwards, up to a time period of 24 $\mathrm{h}$, the intensity of the reflection at $1.6^{\circ} 2 \theta$, which indicates the presence of the nanoporous structure, is reduced, but the very broad reflection in the range from 2.0 to $2.5^{\circ} 2 \theta$ persists. After longer time periods, no diffraction peaks can be observed anymore. Nevertheless, a silica layer is still present which may, for example, still contain drug molecules to be delivered. Also, it is difficult to compare in vitro and in vivo conditions, and the surrounding of an implant in the middle ear directly after implantation is not well defined. Although the middle ear does not contain liquids in a healthy state, blood and iquor may be present directly after the operation. It is therefore difficult to state whether the deterioration of the nanoporous silica layer occurs in a similar way as the in vitro degradation in liquids. Despite this, we can show in the following that a coated implant is able to release an effective amount of ciprofloxacin within the first days after implantation, as supported by animal experiment in rabbits [31].

\section{Drug release}

Bioverit $^{\circledR}$ II platelets as substrates were coated three times using the procedure described in the experimental section. Part of the samples was modified with sulfonic acid groups by first reacting with the silane linker 3-mercaptotrimethoxysilane and subsequent oxidation of the thiol groups with hydrogen peroxide. This chemical modification creates negatively charged groups on the pore surface in order to increase the amount of inserted ciprofloxacin molecules, which are positively charged at $\mathrm{pH}$ 4. This strategy was first derived using glass plates as supports, where in vitro studies showed excellent biocompatibility in cell culture studies and effective antibacterial action in bacterial culture tests [19]. The transfer of this strategy to Bioverit ${ }^{\circledR}$ II supports paved the way for in vivo studies in infected middle ears of rabbits, using middle ear prostheses fabricated from this glass-mica ceramic $[31,32]$.

Both groups of samples (with a nanoporous silica coating and with the additional sulfonate modification) as well as plain non-coated Bioverit ${ }^{\circledR}$ II were loaded with the antibiotic ciprofloxacin and release profiles were recorded by UV-vis measurements in $0.01 \mathrm{M}$ phosphate buffered saline (PBS). The recorded release profiles are shown in Figure 6.

Interestingly, a plain Bioverit $^{\circledR}$ II surface already demonstrated a high drug release amount of $4.5 \mu \mathrm{g} \mathrm{cm}^{-2}$ of the macroscopic surface, revealing the high drug release capacity of the Bioverit ${ }^{\circledR}$ II, which can probably be 
accounted for by the rough surface texture. With the nanoporous coating, only a modest increase up to $5 \mu \mathrm{g} \mathrm{cm}^{-2}$ was achieved. The effect of the sulfonic acid modification can be clearly seen. The amount released was raised nearly twofold up to $9 \mu \mathrm{g} \mathrm{cm}^{-2}$. This is similar to the case in a preceding study with a nanoporous silica layer on glass slides [27]. All samples exhibited a burst release behavior, indicating that ciprofloxacin could freely diffuse out of the pores. This behavior has been shown to be beneficial in an animal experiment, namely an infected middle ear model in rabbits. An infection with $P$. aeruginosa bacteria was effectively antagonized by such a ciprofloxacincarrying implant coating [31]. This result suggests that this type of implant coating is useful to fight middle ear infections which either occur at the time of implantation or which are chronic.

\section{Biocompatibility tests: cell tests and gene expression profiling}

As a representative cell type for bony tissue-implant interactions, the murine mesenchymal precursor cell line C3H10T1/2 was used to establish a cell culture model. Cells were seeded on microscope glass slides, either plane ones or ones coated with an unstructured or a nanoporous silica layer. The material-cell interactions were monitored microscopically. To exclude any interference, serum was omitted from the cell culture medium during the initial cell attachment phase. The cells adhered to

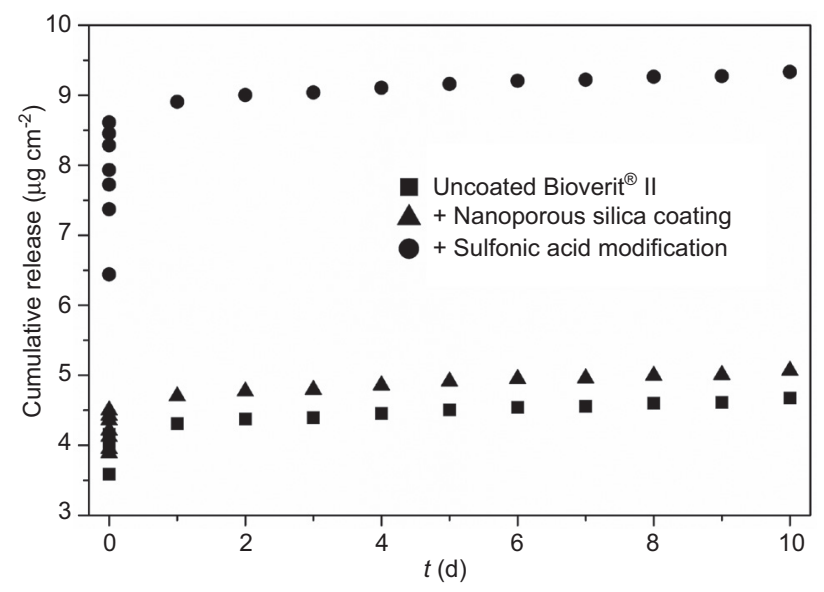

Figure 6 Profiles for the release of ciprofloxacin from plain Bioverit ${ }^{\circledR}$ II substrates (squares), from Bioverit ${ }^{\circledR}$ II substrates coated with a nanoporous silica film (triangles), and from samples with a nanoporous coating which had additionally been modified with sulfonic acid groups (circles). Release experiments were conducted in $0.01 \mathrm{M}$ PBS. The cumulative release is given in mass per $\mathrm{cm}^{-2}$ of the macroscopic substrate surface. both, unstructured as well as nanoporous silica layers, with indistinguishable efficiency. Similarly, during subsequent incubation under standard cell culture conditions, the cells spread out on the coated slides and cell proliferation was similar as on plain glass and almost as high as on cell culture-optimized polystyrene surfaces, independent of the absence or presence of the nanostructure (Figure 7).

In comparison, cells did not adhere to as-synthesized nanostructured silica surfaces, indicating that calcination of the coatings is essential for efficient cell adhesion and cell proliferation (data not shown). This finding is in accordance with the well-known anti-adhesive properties of polyethyleneglycol (PEG) moieties, which are part of the amphiphilic block copolymer and which is removed upon calcination. In conclusion, after calcination the nanoporous silica coating investigated was highly biocompatible and could serve as substrates for various anchorage-dependent cell types.

A further cell culture assay was employed to compare plain Bioverit ${ }^{\circledast}$ II with a material where a nanoporous silica layer was placed on a Bioverit ${ }^{\circledR}$ II support. After $3 \mathrm{~h}$, the mesenchymal precursor cells have attached to both surfaces in a similar manner but have not yet spread out. After 3 days, the cells on plain Bioverit ${ }^{\circledR}$ II have spread very strongly. In comparison, the nanoporous silica layer is slightly less bioactive, shown for example by the presence of some round cells. This slight reduction in bioactivity is understandable with regard to the well-known very high bioactivity of Bioverit ${ }^{\circledR}$ II which does not put in question the good biocompatibility of nanoporous silica.

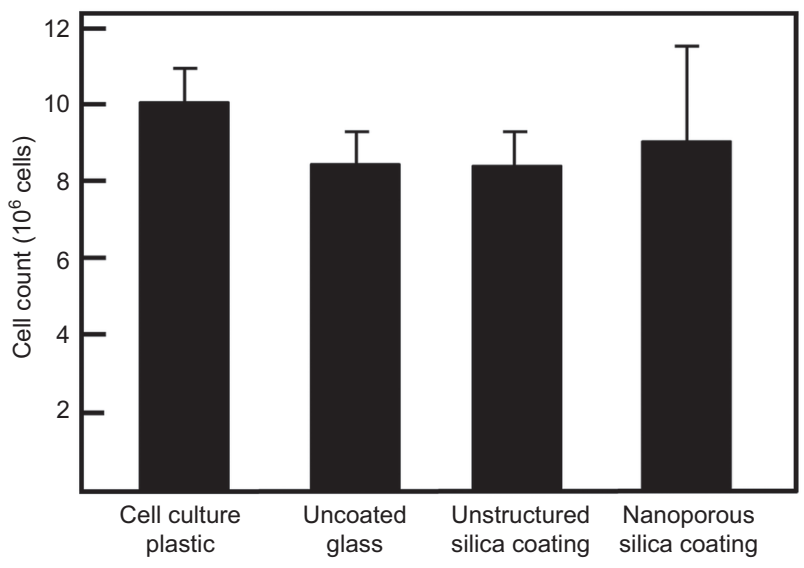

Figure 7 Biocompatibility of nanoporous silica coatings with bone precursor cells. C3H10T1/2 murine mesenchymal precursor cells were seeded on the substrates indicated and incubated under standard cell culture conditions for 3 days. For each substrate the resulting cell density per $\mathrm{cm}^{2}$ is shown. 


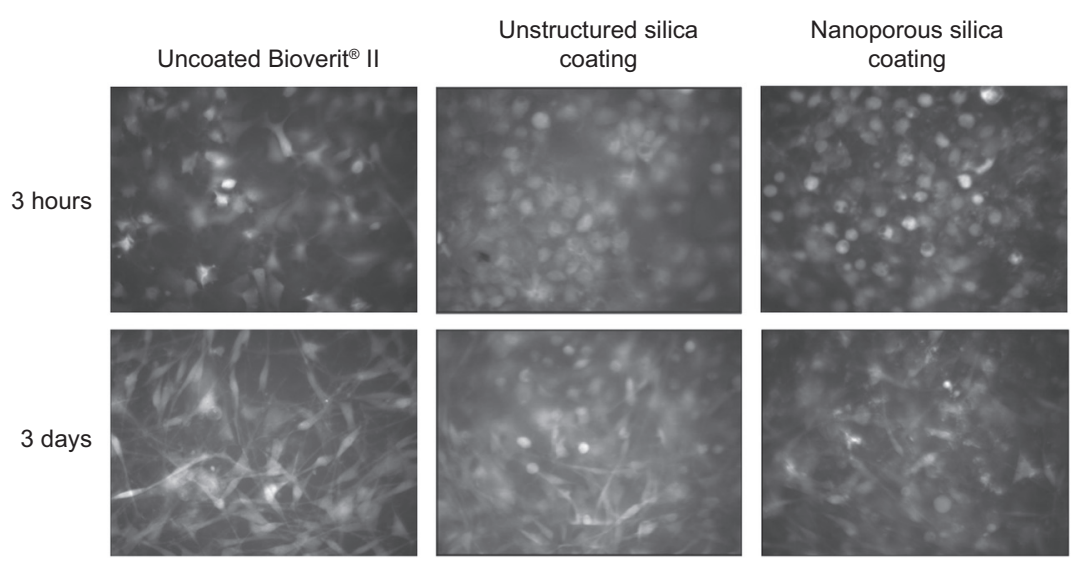

Figure 8 Cell adhesion and cell proliferation on nanoporous silica-coated substrates, eGFP labeled C3H10T1/2 cells, were seeded on plain Bioverit ${ }^{\circledR}$ II, Bioverit ${ }^{\circledR}$ II coated with either an unstructured or with a nanoporous silica layer as indicated. Cell adhesion was determined 3 hours after seeding and cell proliferation after 3 days.

Since cell culture tests cannot predict all in vivo implant properties, animal models are essential for implant material testing. In particular, mice are an extremely well-characterized animal model, allowing both in-depth histological as well as detailed molecular genetics analyses. For molecular characterization of the implant-tissue interactions, a newly established murine middle ear model was adapted [33]. Cylindrical Bioverit ${ }^{\circledR}$ II implants with length and diameter both of $1 \mathrm{~mm}$ were coated with nanoporous silica and were inserted into the middle ear cavity.

The animals recovered from the surgery without complications and appeared healthy. After 2 months the petrous bone which enclosed the implant was removed and the RNA was extracted (Figure 9). The amount of RNA was sufficient and of high quality suitable for gene expression analysis (Figure 10).

The gene expression profiles obtained from middle ears with and without implants were highly related and reproducible. Cluster analysis showed that the method was reliable and sensitive such that even differences between the individual inbred mice could be detected. No significant increase in immune response or inflammatory gene expression could be detected in the presence of the implants, indicating that the nanoporous silica coating was highly biocompatible. These results are in accord with previous histological analyses of Bioverit ${ }^{\circledR}$ II implants coated with a nanoporous silica layer which were conducted in both rabbit and murine animal models [33-35]. Since gene array analysis was able to detect an inflammatory response in the case of iron implants, the method per se is sufficiently sensitive in our hands [36]. Overall, these data indicate that both, Bioverit ${ }^{\circledR}$ II implants as well as nanoporous coatings, did not cause detectable

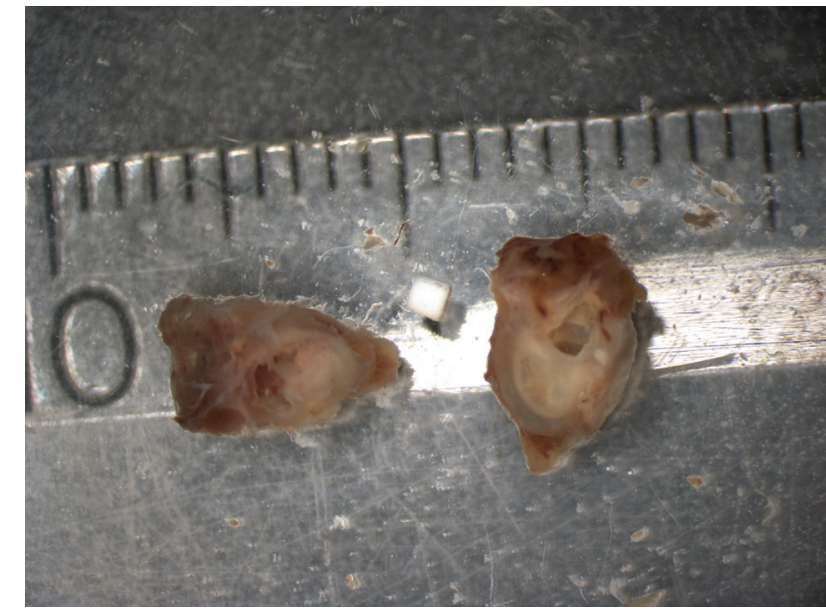

Figure 9 Explanted tissue isolated from mouse middle ears 2 months after implantation. The cylindrical Bioverit ${ }^{\circledR}$ II implant with $1 \mathrm{~mm}$ in diameter and $1 \mathrm{~mm}$ in length is lying between two explanted middle ear samples. RNA was extracted from the tissue and used for whole genomic gene expression analysis.

inflammatory responses in the middle ear of mice. The differences between the data shown in Figure 10, where no significant change in gene expression could be found and the previously published data, where significant changes in response to iron implants were observed, could be interpreted that that Bioverit ${ }^{\circledast}$ II implants and the nanoporous coatings act less inflammatory than iron implants. The view that iron acts more inflammatory than clinically established implant materials was indeed supported by more recent data obtained in our laboratory [37]. Alternatively, it cannot be excluded that the middle ear bone cavity locally contains inflammatory reactions and prevents them from spreading to nearby tissue layers. Since it was not feasible to isolate solely tissue from within the 


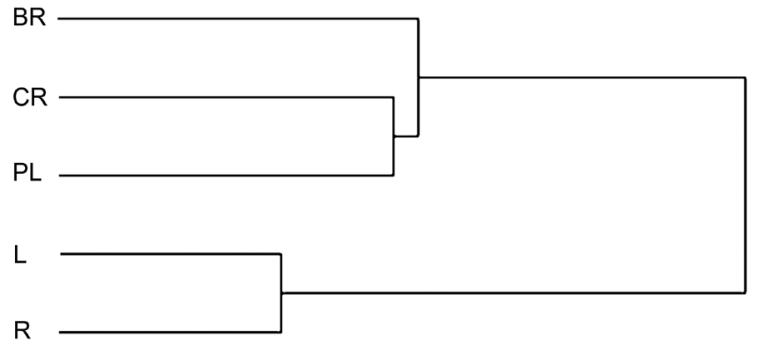

Figure 10 Highly similar gene expression patterns in middle ears with and without nanoporous silica coated implants. Tissue was isolated from mouse middle ears 2 months after implantation of cylindrical implant with $1 \mathrm{~mm}$ in diameter and $1 \mathrm{~mm}$ in length. RNA was extracted from the tissue and used for whole genomic gene expression analysis. An average link cluster analysis of the gene array expression data was done by using the program 'Cluster' from the Eisen lab (http://rana.lbl.gov/EisenSoftware.htm). The differences of gene expression profiles is represented in the graph by the distances of the vertical bars: The implant materials used were as follows: BR, Bioverit ${ }^{\circledast}$ II implant in right ear; CR, Bioverit ${ }^{\circledR}$ II with nanoporous silica coating in right ear; $\mathrm{PL}$, corresponding combined left ears without implants from all mice with implants in the right ear; L, left ear without implant from a mouse without any implants; R: corresponding right ear without implant.

cavity for the gene expression analysis, such an effect may have contributed to limit the detected inflammatory response.

\section{Materials and methods}

\section{Coatings with nanoporous silica}

Two different types of base materials were used as substrates for the coatings, namely glass (Glasbearbeitung Henneberg \& Co., Martinroda, Germany) and Bioverit ${ }^{\circledR}$ II (3di GmbH, Jena, Germany). Absolute ethanol was purchased from Merck (Darmstadt, Germany). All other chemicals were obtained from Sigma-Aldrich Chemie $\mathrm{GmbH}$ (Munich, Germany). All chemicals were used without further purification.

Initial drug release investigations of coated glass substrates were conducted on standard glass slides $(26 \mathrm{~mm} \times 76 \mathrm{~mm} \times 0.95 \mathrm{~mm}$ ) [19]. Due to better handling and high costs of the material, Bioverit ${ }^{\circledR}$ II substrates with size of half a glass slide $(26 \mathrm{~mm} \times 38 \mathrm{~mm}$, height $1.0-1.3 \mathrm{~mm}$ ) were used as supports in further drug release studies. For cell culture testing, coated Bioverit ${ }^{\circledR}$ II discs with a diameter of $9 \mathrm{~mm}$ and 1.5-2.0 mm height were used as a substrate. For quantitative cell culture analyses and stability tests, the dip-coating procedure was applied once to standard microscope glass slides. For implantation into mice, spray-coated Bioverit ${ }^{\circledR}$ II cylinders of $1 \mathrm{~mm}$ diameter and $1 \mathrm{~mm}$ height were used. Prior to the coating, all specimens were cleaned in an ultrasonic bath, first in absolute ethanol and then in acetone for $10 \mathrm{~min}$ each.
The preparation of the nanoporous film has been described elsewhere $[19,27,28]$. The solution used for the preparation of nanostructured silica coatings contained ethanol, water, hydrochloric acid, tetraethoxysilane (TEOS) as a silica source and poly(ethylene glycol)-poly(propylene glycol)-block-co-polymer, (Sigma-Aldrich, $\mathrm{EO}_{20} \mathrm{PO}_{70} \mathrm{EO}_{20}$, average $\mathrm{M}_{\mathrm{n}} \approx 5800$, similar to Pluronic ${ }^{\circledR} \mathrm{P}-123, \mathrm{BASF}$ ) as the structure-directing agent [38]. The dip-coating solution had a molar composition of TEOS: EtOH : $\mathrm{H}_{2} \mathrm{O}: \mathrm{HCl}: \mathrm{EO}_{20} \mathrm{PO}_{70} \mathrm{EO}_{20}=1: 48.9$ : $26.9: 0.06: 0.0135$. It was prepared by adding TEOS to $\mathrm{EO}_{20} \mathrm{PO}_{70} \mathrm{EO}_{20}$ dissolved in a mixture of ethanol, water and hydrochloric acid; the solution was stirred for about $10 \mathrm{~min}$ before coating the specimens. For the preparation of unstructured silica coatings as used for the cell culture assay, a similar solution but without the block-co-polymer was used. Glass and plain Bioverit ${ }^{\circledR}$ II samples were coated using a dip-coating procedure, employing a DC Small Dip-Coater with $75 \mathrm{~mm}$ travel from NIMA (Coventry, England), operated in a climate box at a constant humidity adjusted by $50 \%(\mathrm{w} / \mathrm{w})$ glucose solution. The samples were immersed in the coating solution and then withdrawn perpendicular to the surface of the solution with a speed of approximately $1 \mathrm{~mm} \mathrm{~min}^{-1}$. The samples were then left at constant humidity for $5 \mathrm{~min}$ followed by a drying step at $60^{\circ} \mathrm{C}$ for $30 \mathrm{~min}$. The substrates for drug release experiments from coated Bioverit ${ }^{\circledR}$ II substrates were coated three times. This threefold coating of Bioverit ${ }^{\circledR}$ II substrates is necessary in order to fill the cavities present on the rough surface of this biomaterial and to create a continuous layer. For cell culture experiments and stability tests the glass substrates were coated once. After coating, the specimens were dried at $60^{\circ} \mathrm{C}$ over night, followed by calcination at $415^{\circ} \mathrm{C}$ for $4 \mathrm{~h}$ (rate of heating/cooling $1^{\circ} \mathrm{C} \mathrm{min}^{-1}$ ). For the investigations in the mouse model the specimens were spraycoated instead of using the dip-coating techniques. For this purpose, the cylinders were laid on the plain side and spray-coated with three pumps of a fine disperser followed by a drying step for $30 \mathrm{~min}$ at $60^{\circ} \mathrm{C}$. Afterwards the same procedure was performed to the cylinder lying on the other plain side. Afterwards the samples were treated as described above.

For the drug release studies, the nanoporous silica was modified with sulfonic acid groups and with further silanization reactions to control the release. The corresponding reactions are described in detail elsewhere [19, 39]. In brief, sulfonate groups were established by binding the silane linker 3-mercaptotrimethoxysilane to the silanol groups of the silica surface and by subsequent oxidation of the thiol groups with hydrogen peroxide.

\section{Characterization methods}

X-ray diffraction (XRD) analysis of coated glass substrates and Bioverit $^{\circledR}$ II disks were recorded on a Stoe (Darmstadt, Germany) $\theta / \theta$ diffractometer in reflection geometry using $\mathrm{CuK \alpha}$ radiation and a secondary beam monochromator (graphite). XRD analysis of coated Bioverit ${ }^{\circledast}$ II cylinders was conducted using a Stoe Stadi P powder diffractometer (Stoe \& Cie GmbH, Darmstadt, Germany) in transmission geometry and $\mathrm{CuK \alpha _{1 }}$ radiation $(\lambda=1.540 \AA$ ) $)$. Three Bioverit ${ }^{\circledR}$ II cylinders were inserted in the rotating sample holder.

Scanning transmission electron microscope (STEM) images were collected at $200 \mathrm{keV}$ in high-angle annular dark-field (HAADF) mode on a field-emission instrument of the type JEM-2100F from JEOL Ltd. (Tokyo, Japan). Film on substrate was epoxy-glued against a silicon wafer as counterbody and prepared in cross-section by saw- 
ing, polishing, and final thinning by an argon ion-beam to obtain electron transparent regions.

UV-vis measurements for the determination of ciprofloxacin in $0.01 \mathrm{M}$ PBS were collected on a spectrophotometer UV-mini 1240 (Shimazu, Duisburg, Germany) at a wavelength of $275 \mathrm{~nm}$.

\section{Drug loading and release procedure}

The drug loading and release procedure used have been described in detail elsewhere [19]. Insertion of the antibiotic ciprofloxacin into the nanoporous structure was carried out in a $60 \mathrm{~mm}$ ciprofloxacin solution in hydrochloric acid ( $\mathrm{pH} \mathrm{4)}$. The release experiment was conducted in a $0.01 \mathrm{~m}$ PBS solution. The release measurements were conducted as follows. Five samples were placed into $25 \mathrm{ml}$ of a prewarmed solution $\left(37^{\circ} \mathrm{C}\right)$ of $0.01 \mathrm{M}$ PBS and kept at this temperature. The measurements of the ciprofloxacin concentration in the solution took place after fixed time intervals of 15, 35, 55, 75, 135, 195 and 315 $\mathrm{min}$. Afterwards, the measurements were performed every $24 \mathrm{~h}$. The whole medium was replaced after each measurement to simulate dynamic fluid conditions in the body.

\section{Stability experiments}

In order to investigate the stability of the nanoporous silica film in physiological media we exposed glass samples coated once with the nanoporous silica film to a $10 \%(\mathrm{v} / \mathrm{v})$ fetal calf serum in $0.01 \mathrm{M}$ PBS solution. The experiments were conducted at $37^{\circ} \mathrm{C}$ for different time intervals from 6 to $24 \mathrm{~h}$ mimicking the medium of cell culture experiments. Afterwards, the presence of the nanoporous structure of the film was checked by XRD measurements as presented elsewhere [28]. A sample which had been exposed to fetal calf serum for $12 \mathrm{~h}$, showing an XRD pattern with an intensity reduced reflection at $1.6^{\circ} 2 \theta$ and a novel broad reflection in the range from 2.0 to $2.5^{\circ} 2 \theta$, pointing to a collapse of the nanostructure, was chosen for further investigation by STEM in order to elucidate the rearrangement of the film structure.

\section{Cell culture assays}

NIH3T3 murine fibroblast cells and C3H10T1/2 murine mesenchymal progenitor cells as a bone-related cell line, respectively, were cultured on Bioverit ${ }^{\circledR}$ II (3di, Jena, Germany), glass or nanoporous silica coated microscope slides as substrates for cell attachment. Cells were maintained under standard cell culture conditions in Dulbecco's Modified Eagle Medium (DMEM, Gibco BRL Life Technologies, Eggenstein, Germany) with fetal calf serum (FCS; Cytogen, Berlin, Germany) at $37^{\circ} \mathrm{C}$ with $5 \% \mathrm{CO}_{2}$ The various cell substrates were sterilized by incubation in $100 \%$ ethanol for $5 \mathrm{~min}$, and then rinsed with PBS ( $\mathrm{pH}$ 7.4). To determine the ability of cells to adhere to nanoporous coatings, cells were seeded at a density of $10^{4} \mathrm{~cm}^{-2}$ and incubated in DMEM without FCS at $37^{\circ} \mathrm{C}$ with $5 \% \mathrm{CO}_{2}$ for $30 \mathrm{~min}$. Adherent cells were photographed using an inverted light microscope (Zeiss, Oberkochen, Germany). The cell density was estimated by manually counting the cells. Subsequently, 10\% (v/v) FCS was added to the cell culture medium and the cells were incubated for 3 additional days to determine cell proliferation.

To monitor cell-implant interactions, a stably transfected murine mesenchymal precursor cell line $\mathrm{C} 3 \mathrm{H} 10 \mathrm{~T} 1 / 2$ expressing green fluorescent protein (eGFP) from the constitutive SV40 promoter (BD Bioscience/Clontech) was used. Implant materials were disinfected by incubation in ethanol for $24 \mathrm{~h}$ prior to use. The material samples were transferred to standard tissue culture wells (Costar 24 well culture cluster, Corning Incorporated, Corning, NY, USA). eGFP-labeled $\mathrm{C} \mathrm{H}_{10 \mathrm{~T}} 1 / 2$ cells were then seeded onto the material samples at a density of $2 \times 10^{4} \mathrm{~cm}^{-2}$ and incubated in serum-free DMEM at $37^{\circ} \mathrm{C}$ in a humidified atmosphere with $5 \% \mathrm{CO}_{2}$. Cell adhesion was determined by UV-fluorescence microscopy with an excitation light band-pass filter of 405-495 nm and a FITC emission filter (535AF45; Omega Optical; Optophotonics, Eaubonne, France). To determine cell proliferation, fetal calf serum was subsequently added to a final volume of $10 \%$ of the cell culture medium and the cells were incubated further. Cell spreading and cell proliferation were examined after $3 \mathrm{~h}, 1$ day and 3 days after seeding, respectively.

\section{Implantation procedure}

Female BALB/c mice (Harlan Winkelmann GmbH, Borchen, Germany) of 16-22 $\mathrm{g}$ body weight each were kept in groups of 1-5 mice in individually aerated cages and fed a standard laboratory diet. Surgery was done as described previously [33]. Briefly, the animals were anesthetized by intraperitoneal injection of $10 \mathrm{mg} \mathrm{kg}^{-1}$ xylazin (Rompun ${ }^{\circledR} \%$, Bayer Vital GmbH, Leverkusen, Germany) and $100 \mathrm{mg} \mathrm{kg}^{-1}$ ketamin (Albrecht, Aulendorf, Germany) and $5 \mathrm{mg} \mathrm{kg}^{-1}$ of carprofen (Rimadyl, Pfizer Pharma GmbH, Karlsruhe, Germany). Surgery of the left ear was performed with the aid of a binocular (SV11 stereoscopic zoom microscope, Zeiss, Oberkochen, Germany). The tympanic cavity was opened with a hypodermic needle and the cylinder inserted as a plug in the hole. Bioverit ${ }^{\circledR}$ II cylinders of $1 \mathrm{~mm}$ diameter and $1 \mathrm{~mm}$ height, respectively, with or without the nanoporous silica coating were inserted into the middle ear by puncturing the bulla tympanica of the left ear. The implanted Bioverit ${ }^{\circledR}$ II cylinders were in contact with the bony structure of the middle ear cavity at undefined locations. After 2, 6 and 12 weeks, respectively, the petrous bone was removed. The wound was closed by using an absorbable suture (Ethicon Vicryl ${ }^{\circledR}$ 5-0 or 6-0; Johnson+Johnson Intl, Brussels, Belgium). Antibiotics trimethoprim and sulphonamide (0.5\% Cotrim-K; Ratiopharm GmbH, Ulm, Germany) were supplied in the drinking water for 7 days following the surgery. All animal experimentation was performed under the permission AZ 33.42502/07 of the local authorities (Bezirksregierung Braunschweig, Dezernat 509, Braunschweig).

\section{Gene expression profiling}

Mice were decapitated and the petrous bone with a small amount of adhering tissue was surgically removed and immediately frozen in liquid nitrogen. The frozen samples were crushed with a pestle in a ceramic mortar while still in the presence of liquid nitrogen. The samples were further processed as previously described [36]. Briefly, total RNA was isolated from the frozen powder with a kit according to the manufacturer's instructions (Rneasy Mini Kit, Qiagen; Hilden, Germany). RNA was resuspended in water and the concentration and purity determined using a NanoDrop ND-1000 analyser (Peqlab Biotechnologie GmbH, Erlangen, Germany). RNA integrity was determined by gel electrophoresis with the Nano Assay (Agilent 2100 Bioanalyzer, Agilent Technologies; Waldbronn, Germany). RNA expression profiling was performed as previously 
described [40, 41]. Probes for hybridization were synthesized according to the manufacturer's protocol as follows (Affymetrix; Santa Clara, CA). From $3 \mu \mathrm{g}$ of total RNA biotin-labeled target synthesis reactions were performed. Briefly, $3 \mu \mathrm{g}$ total RNA were converted to dsDNA using 100 pmol of a T7T23V primer (Eurogentec; Seraing, Belgium) containing T7 promoter sequences. The cDNA was then used directly in an in vitro transcription reaction in the presence of biotinylated nucleotides. The concentration of biotin-labeled cRNA was determined by UV absorbance. $12.5 \mu \mathrm{g}$ of biotinylated cRNA preparation was fragmented and placed in a hybridization cocktail with four biotinylated hybridization control probes (BioB, BioC, BioD, and Cre). Samples were hybridized to an identical lot of Affymetrix GeneChip MOE430 2.0 for $16 \mathrm{~h}$. After hybridization, the chips were washed, stained with SA-PE and read using an Affymetrix GeneChip fluidic station and scanner with Affymetrix standard software GCOS 1.2 GeneChip ${ }^{\circledR}$ Operating Software that controls the fluidics stations and scanner (Affymetrix; Santa Clara, CA, USA). All experiments were scaled to a target intensity of 150 using the preset default values of GCOS 1.2. For the significance ranking of the GO categories the list of ProbesetIDs with twofold or higher differences were analyzed with the program DAVID using a derivative of Fisher's Exact probability test [42]. Clustering analysis was performed using the program Gene Cluster 3.0. For hierarchical average linkage clustering the array data was log transformed, genes and arrays median centered and then normalized. The associated program TreeView was employed to graphically represent the clustering data [43].

\section{Conclusions}

This paper presents basic results on nanoporous silica coatings with the perspective to use these multifunctional layers on implants. For the in-depth characterization of these layers glass slides were used as supports, whereas for more applied studies, the well-established biomaterial Bioverit ${ }^{\circledR}$ II was used.

X-ray diffraction as well as scanning transmission electron microscopic studies show that the coatings have a disordered pore structure which is however regular with regard to the pore diameter. Our data shows that the nanoporous silica coatings are highly biocompatible in cell culture assays as well as in vivo in a mouse ear model. Therefore, nanoporous silica coatings that could be loaded with bioactive compounds appear as a promising strategy to add functionality to implants. The nanostructure of the porous coating is only stable up to $12 \mathrm{~h}$ in physiological media, as is indicated by the disappearance of the characteristic XRD reflections and as was observed before [30]; modification of the silica surface can prolong that time. After the disappearance of the characteristic XRD reflections, an unstructured silica layer remains which still shows favorable properties with regard to the activity of bound enzymes [27], for drug release (as shown here and in ref [19]) and for the delivery of bioactive molecules as the bone morphogenetic protein BMP2 [28]. Cultured cells could attach, spread and proliferate efficiently on the nanoporous coating (this paper and [34]). In the middle ear cavity of mice, Bioverit ${ }^{\circledR}$ II samples with a nanoporous coating did not provoke any significant inflammatory reaction as substantiated here by the modern method of whole genome expression profiling. These results, together with data from animal experiments using rabbits [subcutaneous and in the middle ear [33-35], show that the nanoporous silica coating is highly biocompatible. The internal space and the increased surface area have shown to be highly suitable for applications as a drug reservoir for the binding and presenting bioactive substances [19, 27, 28].

Acknowledgements: This work was supported by the DFG within the Collaborative Research Program SFB 599 'Sustainable bioresorbable and permanent implants based on metallic and ceramic materials'. We thank our colleagues from the work package D1 for interesting discussions. Furthermore we thank Tanja Heemeier for support by carrying out the preparation of samples and recording of release profiles.

Received March 6, 2013; accepted March 13, 2013; previously published online May 28, 2013

\section{References}

1. Beleites E, Gudziol H, Höland W. Maschinell bearbeitbare Glaskeramik in der Kopf-Hals-Chirurgie. HNO-Praxis 1988;13:121-5.

2. Beleites B, Rechenbach G. Implantologie in der Kopf-HalsChirurgie - gegenwärtiger Stand. In: Ganz H, Schätzle W, editors. HNO-Praxis Heute. Heidelberg, Germany: Springer Verlag, 1992; pp. 170-99.
3. Jütte M, Klein S, Katenkamp D, Vogel W, Götz W, Woytinas R. Ergeb-nisse der tierexperimentellen Erprobung einer neuen Enukleationsplombe aus Biovitrokeramik - Bioverit I und II (bioaktiv und biokompatibel). Klin Monatsbl Augenheilkd 1992;200:674-7.

4. Samy RN, Pensak ML. Revision ossiculoplasty. Otolaryngol Clinics North Am 2006;39:699-712. 
5. Höland W, Vogel W, Naumann K, Gummel J. Interface reactions between machinable bioactive glass-ceramics and bone. J Biomed Mater Res 1985;19:303-12.

6. Dost $P$, Jahnke K. Biomaterials in reconstructive middle ear surgery. In: Jahnke K, editor. Middle ear surgery: recent advances and future directions. Stuttgart, Germany: Georg Thieme Verlag, 2003:53-70.

7. Klein M, Glatzer C. Individual CAD/CAM fabricated glassbioceramic implants in reconstructive surgery of the bony orbital floor. Plastic Reconstructive Surgery 2006;117:565-70.

8. Siebert H, Schleier P, Beinemann J, Fried W, Zenk W, Schumann D. Evaluation of individual ceramic implants made of Bioverit with CAD/CAM technology to reconstruct multidimensional craniofacial defects of the human skull. Mund-, Kiefer- und Gesichtschirur-gie 2006;10:185-91.

9. Schneider G, Blechschmidt K, Linde D, Litschko P, Körbs T, Beleites $\mathrm{E}$. Bone regeneration with glass ceramic implants and calcium phosphate cements in a rabbit cranial defect model. J Mater Sci Mater Med 2010;21:2853-9.

10. Ganesan B, Webster TJ. Nanotechnology and biomaterials for orthopedic medical applications. Nanomedcine 2006;1:169-76.

11. Raman NK, Anderson MT, Brinker CJ. Template-based approaches to the preparation of amorphous, nanoporous silicas. Chem Mater 1996;8:1682-701.

12. Tang F, Li L, Chen D. Mesoporous silica nanoparticles: synthesis, biocompatibility and drug delivery. Adv Mater 2012;24:1504-34.

13. Arcos D, Vallet-Regí $M$. Solgel silica-based biomaterials and bone tissue regeneration. Acta Biomater 2010;6:2874-88.

14. Vallet-Regí M, Colilla M, González B. Medical applications of organic-inorganic hybrid materials within the field of silica-based bioceramics. Chem Soc Rev 2011;40:596-607.

15. Vallet-Regí M. Nanostructured mesoporous silica matrices in nanomedicine. J Inter Med 2010;267:22-43.

16. Soler-Illia GJ, Crepaldi EL, Grosso D, Sanchez C. Block copolymer-templated mesoporous oxides. Curr Opin Colloid Interf Sci 2003;8:109-26.

17. Sanchez C, Boissière C, Grosso D, Laberty C, Nicole L. Design, synthesis, and properties of inorganic and hybrid thin films having periodically organized nanoporosity. Chem Mater 2008;20:682-737.

18. Lebold T, Jung C, Michaelis J, Bräuchle C. Nanostructured silica materials as drug-delivery systems for doxorubicin: single molecule and cellular studies 2009. Nano Letters 2009;9: 2877-83.

19. Ehlert N, Badar M, Christel A, Jare Lohmeier S, Luessenhop T, Stieve M, et al. Mesoporous silica coatings for controlled release of the antibiotic ciprofloxacin from implants. J Mater Chem 2011;21:752.

20. Scheithauer S, Häfner H, Lemmen SW. The current pathogen spectrum - what are we fighting against? Der Orthopäde 2012;41:6-10.

21. Bazaka K, Jacob MV, Crawford RJ, Ivanova EP. Efficient surface modification of biomaterial to prevent biofilm formation and the attachment of microorganisms. Appl Microbiol Biotechnol 2012;95:299-311.

22. Beck JS, Vartuli JC, Roth WJ, Leonowicz ME, Kresge CT, Schmitt KD, et al. A new family of mesoporous molecular sieves prepared with liquid crystal templates. J Am Chem Soc 1992;114:10834-43.
23. Kresge CT, Leonowicz ME, Roth WJ, Vartuli JC, Beck JS. Ordered mesoporous molecular-sieves synthezised by a liquid-crystal template mechanism. Nature 1992;359:710-2.

24. Behrens P, Glaue A, Haggenmüller C, Schechner G. Structuredirected materials syntheses: synthesis field diagrams for the preparation of mesostructured silicas. Solid State Ionics 1997;101-3:255-60.

25. Hoffmann F, Cornelius M, Morell J, Fröba M. Silica-based mesoporous organic-inorganic hybrid materials. Angew Chem Int Ed 2006;45:3216-351.

26. Brinker CJ, Lu Y, Sellinger A, Fan H. Evaporation-induced selfassembly: nanostructures made easy. Adv Mater 1999;11:579-85.

27. Ehlert N, Müller PP, Stieve M, Behrens P. Immobilization of alkaline phosphatase on modified silica coatings. Microporous Mesoporous Mater 2010;131:51-7.

28. Ehlert N, Hoffmann A, Luessenhop T, Gross G, Mueller PP, Stieve M, et al. Amino-modified silica surfaces efficiently immobilize bone morphogenetic protein 2 (BMP2) for medical purposes. Acta Biomater 2011;7:1772-9.

29. Kim JM, Kwak JH, Jun S, Ryoo R. Ion exchange and thermal stability of MCM-41. J Phys Chem 1995;99:16742-7.

30. Bass JD, Grosso D, Boissiere C, Belamie E, Coradin T, Sanchez C. Stability of mesoporous oxide and mixed metal oxide materials under biologically relevant conditions. Chem Mater 2007;19:4349-56.

31. Lensing R, Bleich A, Smoczek A, Glage S, Ehlert N, Luessenhop T, et al. Efficacy of nanoporous silica coatings on middle ear prostheses as a delivery system for antibiotics: an animal study in rabbits. Acta Biomater 2013;9:4815-25.

32. Hesse D, Ehlert N, Smoczek A, Glage S, Luessenhop T, Behrens P, et al. Nanoporous silica coatings as a drug delivery system for ciprofloxacin: outcome of variable release rates in the infected middle ear of rabbits. Otology Neurotology, accepted for publication, 2012.

33. Vogt JC, Brandes G, Ehlert N, Behrens P, Nolte I, Mueller PP, et al. Free Bioverit II implants coated with a nanoporous silica layer in a mouse ear model - a histological study. J Biomater Appl 2009;24:175-91.

34. Turck C, Brandes G, Krueger I, Behrens P, Mojallal H, Lenarz T, et al. Histological evaluation of novel ossicular chain replacement prostheses: an animal study in rabbits. Acta Oto-Laryngol 2007;127:801-8.

35. Vogt JC, Brandes G, Krüger I, Behrens P, Nolte I, Lenarz T, et al. A comparison of different nanostructured biomaterials in subcutaneous tissue. J Mater Sci Mater Med 2008;19:2629-36.

36. Mueller PP, Arnold S, Badar M, Bormann D, Bach FW, Drynda A, et al. Histological and molecular evaluation of iron as degradable medical implant material in a murine animal model. J Biomed Mater Res Part A 2012;100:2881-9.

37. Badar M, Lünsdorf H, Evertz F, Rahim MI, Glasmacher B, Hauser H, Mueller PP. Formation of an organic coat on metallic magnesium implants and detection of corrosion microparticles in the surrounding tissue. Acta Biomater 2013; http://dx.doi. org/10.1016/j.actbio.2013.03.012.

38. Chen X, Wang Y, Zhou J, Yan W, Li X, Zhu JJ. Electrochemical impedance immunosensor based on three-dimensionally ordered macroporous gold film. Film 2008;80:2133-40.

39. Marschall R, Bannat I, Caro J, Wark M. Proton conductivity of sulfonic acid functionalized mesoporous materials. Microporous Mesoporous Mater 2007;99:190-6. 
40. May T, Hauser H, Wirth D. Transcriptional control of SV40 T-antigen expression allows a complete reversion of immortalization. Nucleic Acids Res 2004;32:5529-38.

41. Mueller PP, May T, Perz A, Hauser H, Peuster M. Control of smooth muscle cell proliferation by ferrous iron. Biomaterials 2006;27:2193-200.
42. Dennis G, Sherman BT, Hosack DA, Yang J, Gao W, Lane HC, et al. DAVID: database for annotation, visualization, and integrated discovery. Genome Biol 2003;4:P3.

43. Eisen MB, Spellman PT, Brown PO, Botstein D. Cluster analysis and display of genome-wide expression patterns. Proc Natl Acad Sci USA 1998;95:14863-8. 